\title{
On Site Selection of Jianchuan Grottoes
}

\author{
Chunji Zhang \\ Sichuan Fine Arts Institute \\ Chongqing, China \\ Ceramic Institutes of Jingdezhen \\ Jingdezhen, China
}

\begin{abstract}
Jianchuan Shizhongshan Grottoes were the largest Buddhism grotto during Nanzhao and Dali Kingdoms, which are located in Shizhongshan Mountain of Shibaoshan Mountain, $30.5 \mathrm{~km}$ southwest from Jianchuan County, Dali Bai Autonomous Prefecture, Yunnan Province. The paper introduces the compelling reason of formation of Jianchuan Grottoes, whose important reason of selecting site was that the shape of Shizhong Mountain was like the head sculpture of Sakyamuni very much, which made a natural Buddha head.
\end{abstract}

Keywords_Jianchuan grottoes; site selection; shallow analysis

\section{INTRODUCTION}

China's grotto art rose with the introduction of Buddhism into China, and had close connection to politics, economy, philosophy, ethics, culture and art of past dynasties of China.

Open the distribution map of China's grottoes, there is "Sanxian Cave" in Kashgar, Xinjiang, "Kizil Grottoes" in Baicheng, "Kezinaiha Thousand-Buddha Cave" and "Kumtura Thousand-Buddha Cave" in Kuqa. There are "Dunhuang Mogao Grottoes" in Longxi, Gansu, "Wenshushan ThousandBuddha Cave" in Jiuquan on Hexi Corridor, and "Tiantishan Grottoes" in Wuwei. It develops into northern and southern routes from the west end of Qinling Mountains, there are grottoes like "Shikong Temple" and "Xumishan Mountain" in Ningxia, "Fenzhou Giant Buddhist Temple", "ThousandBuddha Temple" and "Qingliangshan Mountain" in Shaanxi, "Hongqing Temple" and "Longmen" in He'nan, "Thousand Buddha Rock" in Hebei, various grottoes the Northern Wei Dynasty like "Tianlongshan Mountain" and "Yun'gang" in Shanxi, "Baifoshan Mountain" and "Wufengshan Mountain" in Shandong. In the southern route, it crosses Qinling Mountain and enters Sichuan Basin, and many grottoes are distributed along the sides of Minjiang River, Tuojiang River and Jianglingjiang River basins. These grottoes mostly enter from the "Silk Roads", and were formed under the influence of "Northern Buddhism" dominated by Mahayana.

There were also other routes of Buddhism to be introduced to China: from India to Burma, to Yunnan and then Sichuan, according to documentary records and modern archaeological discovery, this route of "Southern Buddhism" dominated by Hinayana did exist, and it might be earlier than the route of the "northern" one. But now little trace remains, and its influence on Chinese Buddhism is also inferior to "Northern Buddhism". During Dali Kingdom there had been Shizhongshan Grottoes, Jinhuasan Grottoes and Luoyangshan Grottoes, and the most representative ones were still Shizhongshan Grottoes in Shibaoshan Mountain in Jianchuan.

\section{ANALYSIS ON IMPORTANT REASONS FOR SITE SELECTION OF JIANCHUAN GROTTOES}

The Jianchuan is a little remote, the reason why a grotto in different shape was sculptured here were as follow:

\section{A. The Appearance of Shibaoshan Mountain Was Like the Head Sculpture of Buddha}

The special geographic phenomenon of Shibaoshan Mountain shaped it unique mountain shape. There was a small hill on the west side of Jianchuan Grottoes, whose shape was like stone bell (Shizhongshan Mountain got the name for this), but was more like the head sculpture of Shakyamuni. Its bottom was on an inclined mountain, where the shape of a huge human face could be distinguished. It was a peculiar mountain surface. The mountain appearance of Shibaoshan Mountain naturally formed constituted more Buddha head sculptures, and there were many ones naturally formed in Shiziguan, Baoxiang Temple and Ciyun Temple "Fig. 1". We can also guess that it was because there was such a largest natural figurative head sculpture of Shakyamuni in the world in Shibaoshan Mountain that grottoes of Buddhism successively appeared on Shibaoshan Mountain (Shizhong Temple, Shadengjing ans Shizi) and special mountain shapes nearby. It is not hard to understand that people then valued the terrain of Shibaoshan Mountain and thus made statues here for worship.

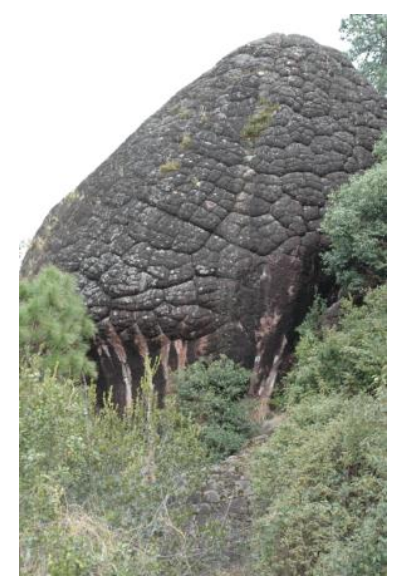

Fig. 1. Shizhongshan Mountain in the shape of Buddha head 
Shibaoshan Mountain has remarkable meaning for local primitive religion, which consecrates "Ayangbai" "Fig. 2", the primitive female genitalia worshiped by local nations and the images of Buddha together on lotus thrones inside Shizhongshan Grottoes. The annual singing festival and Lingquan on Shibaoshan Mountain reflect that it has incomparable status among local residents, which can be said to be the location for local nations to consecrate primitive religion. Buddhism grottoes' appearance in Shibaoshan Mountain was Buddhism's application of primitive religion sacrificial place.

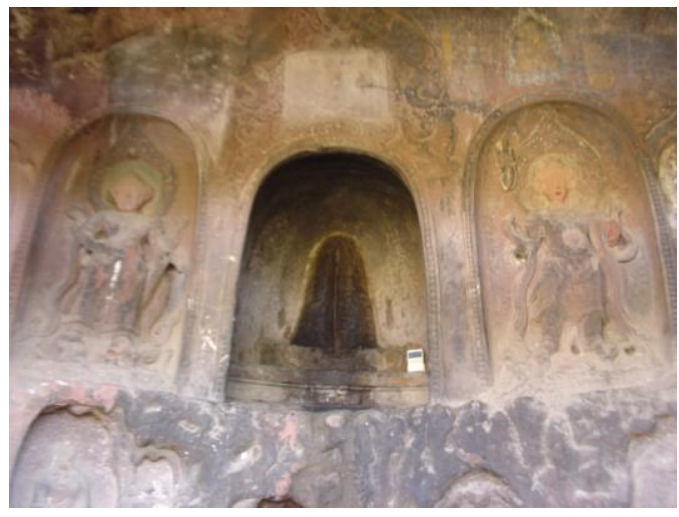

Fig. 2. Ayangbai in No.1 grotto in Shizhongshan Mountain

\section{B. Shibaoshan Mountain is Located on Vital Communication Line}

Shizhongshan Mountain is located in important position of north-south route. Jianchuan goes north to Lijiang and then Sichuan, goes south to Shaxi via Shizhongshan Mountain, or goes east to Eryuan and then Dali, or goes south to Qiaohou, Yunlong and then Baoshan and Burma. This route is one of the important routes for Yunnan, especially northwest Yunnan to connect the hinterland, Tibet, Burma and India. In remote antiquity, some tribes of Qiang ethnic minority went from Hehuang in Gansu, Qinghai areas to Yunnan along this route; in Tang Dynasty, Tubo army went south mainly along with route and fought to territory with Tang Dynasty and Nanzhao. Nanzhao army went north along this route to fight with Tubo and Tang, Kublai Khan also went south to fight with Dali Kingdom along this route.

\section{Shibaoshan Mountain Area Has Economic and Strategic Advantages}

Qiaohou near Shizhongshan Mountain was an important place for Nanzhao to control salt mine. The salt mine was the most important mine in Nanzhao economy, also very important to people's life, social stability and national security. Jianchuan was the most important producing area of salt in Nanzhao with many salt mines, and was nearer to Dali than other salt mines like Annning, Chuxiong, Dayao, Yaoan and Sichuan.

Shizhongshan Mountain was located in an important central hub location of local government of Jiannan, various salt wells and Dali with important strategic position. Such important geographic position made kings and royals of
Nanzhao came to Shizhongshan Mountain for supervision in person from time to time, also officials and soldiers of all layers went through it, and even more salt miners, businessmen, employees and street vendors came and went through it. Also Jianchuan had cool and pleasant weather, beautiful but not precipitous mountains, and proper distance from Dali, the capital at that time. Such a natural environment naturally made a summer resort for royals of Nanzhao. For Nanzhao nobility who believed in Buddhism, building temporary imperial palaces and temples in their region was quite normal.

Jianchuan Shizhongshan Grottoes were dug between 9th and 12th Century, when Buddhism prevailed in Nanzhao and Dali with unification of the state and the church. According to the record of "Shirakuni reason", "In 3rd year of Zhenguan period in Tang Dynasty, the Taoist master observed stars and submitted memorials that 'there is a king rising in southwest.' The emperor asked him to visit. Xi'nuluo shew up and became king of Shirakuni... There was suddenly a Jin'gu bird which flew to the right shoulder of Nuluo, and twittered 'Heaven appointed Xi'nuluo' for 3 times and people were all amazed. Nuluo then ascended the throne and was called as Qi King and paid tribute to Tang Dynasty. All his descendants claimed throne and it was handed down till Shunhuazhen, 13 generations and 237 years in total. During Xi'nuluo's reign in Dali, people were happy and easy, men farmed and women weaved, everyone worked in contentment". In the 9th century, Nanzhao despoiled the area and regime of Wuzhao, and gradually set up a relatively stable political and economic environment. To solidify the regime, building religious grottoes became an important spiritual method of advertising and solidifying dominant position and stabilizing people. Governors of Nanzhao supported and advocated Buddhism after succeeding to the throne, which enabled the construction of Shizhongshan Grottoes to last 300 years. Politics made it possible to construct religious grottoes, and foreign Buddhism enriched the religious art inside the grottoes.

Shizhongshan Grottoes became a kind of religious art dominated by Buddhism content. As a product of religion, grottoes' direct objective and detailed content was bound to be advertising and reflecting religious doctrine and dogmata. Dali Kingdom was located in southwest borderland, which was a vital communication line leading to India and bordered Burma. Indian Buddhism from India, Han Buddhism from hinterland, Tibetan Buddhism, and Theravada Buddhism from Southeast Asia all gathered here. They consisted themes of various images of Buddha and life themes for Yunnan Jianchuan Grottoes.

Developed economic communication supported the construction of grottoes, and abundant local handicraftsmen became even an indispensable important condition for construction of grottoes. Shizhongshan Mountain had important strategic status, and salt merchants, tea merchants and Burmese jade merchants all promoted the development of local economy. People delivering goods on various trade routes passed through here. People's belief in religion offered great folk economic support to the construction of grottoes apart from the political and economic supports from royals. 


\section{Craftsman of Shibaoshan Mountain Area Had Technical Advantage}

Jianchuan is now a national famous hometown of wood carving. The cradleland of Yunnan's bronze culture (over 4500 years from now) was in Haimenkou site in Jianchuan. Excellent traditional folk craftsmen like carpenters and stonemasons contributed their own power to the digging of grottoes. Local people also believed in Buddhism, which made them devoted to the construction of grottoes.

\section{CONCLUSION}

Such geographic feature and position, and such political and economic condition were bound to make Jianchuan a spot at that time, and it became inevitable to build Buddhism grottoes there. And the so-called head sculpture of Shakyamuni formed by stone bell on Shizhongshan Mountain was the important reason why the grottoes selected that site.

\section{REFERENCES}

[1] "Discussion on Nanzhao culture". Chief editors: Yang Zhonglu, Zhang Fusan, Zhangnan, Yunnan People's Publishing House, 1991.5.

[2] "Jianchuan Grottoes". Written by Ouyang Chun (the Bai nationality), photographed by Chen Pu (the Yi nationality), Yunnan Art Publishing Pres, 1985.9.

[3] "Jianchuan Shizhongshan grottoes: southern treasure" (Yunnan Art Publishing Pres, 1998.8), compiled by Culture and Sports Bureau of Jianchuan County, Yunnan.

[4] "Textual criticisms and explanations on Jianchuan Shibaoshan Mountain”, Yunnan Nationalities Publishing House, 1999.3, first version.

[5] "Stories of Shibaoshan Mountain and Jianchuan carpenters". Chief editors: Zhang Wen, Chen Ruihong, Yunnan Nationalities Publishing House, 2003.10, first version.

[6] "Jianchuan Grottoes: brief report on archaeological survey in 1999", Group of Archaeological Research on Jianchuan Grottoes of Department of Archaeology of Peking University and Department of History of Yunnan University.

[7] "Analysis on cause of Jianchuan Shizhongshan Grottoes". Duan Bingchang (the Bai nationality), (paper in International Seminar on Jianchuan Shizhongshan Grottoes in Yunnan).

[8] "Grotto art and Dressing system of Nanzhao and Dali kingdoms". Lin Quan (paper in International Seminar on Jianchuan Shizhongshan Grottoes in Yunnan).

[9] "Some conjectures and doubts on Jianchuan Grotto art". Xie Shengbao (paper in International Seminar on Jianchuan Shizhongshan Grottoes in Yunna.

[10] "Discussion on relation between Yunnan and Dazu Grottoes". Dong Dengjin (paper in International Seminar on Jianchuan Shizhongshan Grottoes in Yunnan. 